\title{
Analysis of Interrelated Factors Affecting Efficiency and Stability of Power Supply in Nigeria
}

\author{
J. Y. Oricha*, G. A. Olarinoye \\ Department of Electrical and Computer Engineering, Ahmadu Bello University, Zaria, 810006, Nigeria
}

\begin{abstract}
In order to have stable and improve efficiency in power supply, there is need to analyse and understand the complex interrelated factors affecting the efficiency and stability of power supply. The factors that affect the efficacy and stability of power supply in any developing country/region could be classified as follows: government policy; economy factor; natural factor; society/community factor; effective energy management; skilled personnel; efficient technology and security factor. All these factors mentioned above have direct or indirect influence on the stability and efficiency of power supply. Various numbers of complicating factors that can prevent restructuring of energy sector to create electricity market that can improve efficiency of power supply in Nigeria are analysed. Suggestions of steps or actions that should be taken into consideration before proposing solutions to some of the problems of power sector are also highlighted in this paper.
\end{abstract}

Keywords Management, Power Grid, Government Policy, Investment, Regulation, Efficient Technology

\section{Introduction}

Stable and efficient power supply in any nation is the key to economic growth in that nation. Nigeria is facing enormous technical, management and economic problems in energy sector that calls for an urgent special approach. In order to find engineering/management solutions to power system problems, it is inevitable to carry out technical and management analysis of interrelated factors that have great impact on the smooth operation of the energy sector as a whole. It is important to note that the problems affecting energy sector in developing countries differ from the problems that influence the same energy sector in developed countries. In view of these differences, it will be difficult to achieve economic efficiency in developing countries, following the same pattern of restructuring and deregulation of energy sector in developed countries.

\section{Factors Affecting Stability and Efficiency of Power Supply}

\subsection{Government Policy}

Government policy could be grouped into three categories as follows: energy policy; fiscal policy and monetary policy. Detailed explanation on how these policies affect the

* Corresponding author:

okaitojyo@yahoo.co.uk (Joseph Yakubu Oricha)

Published online at http://journal.sapub.org/ijee

Copyright (C) 2012 Scientific \& Academic Publishing. All Rights Reserved stability and efficiency of power supply, most especially in developing countries are analysed below.

\subsubsection{Energy policy}

\section{i. Direct Investment in Energy Sector}

There are several ways government policy could influence the stability of power supply. Energy policy could be direct investment in energy sector for future expansion and modernization of the generating units, transmission and distribution units. Another form of this energy policy could also be a kind of passing a bill by the government that will enforce the participation of private, cooperate organizations in generation, transmission and distribution of electrical energy. An example of this approach could be seen in recent years when Nigerian government passed a bill that made it compulsory for all major oil companies in the country to be investing in independent power generation projects to boost the existing generation capacity. To increase investment in power generation, this bill passed by the Nigerian government in my own opinion, should not be limited to major oil companies alone but should be extended to all financial institutions, government parastatals, industries and private organizations.

In the United Kingdom, there was heavy investment in energy sector which resulted in power generation in excess of power demand. When the country realized that there was sufficient generation capacity, the energy sector was unbundled to introduce competition. This is one of the factors that contributed greatly to a successful restructuring of energy sector and creation of electricity market in the United Kingdom[1]. The main goal of restructuring energy sector in Nigeria is to bring about cost reduction and improve 
efficiency of power supply through the use of modern technologies. This could only be achieved if there is sufficient investments fund. It is important to note that even in developed countries; power sector is not attractive to investors. Therefore, government's strong energy policy through direct investment will be the only way to achieve the level of investments needed for improvement of power generation capacity and modernization of the energy infrastructure.

ii. Deregulation of Energy Sector

The role of deregulation is to structure a competitive market with enough generators to eliminate market power of monopolist. Also it is clear, that with deregulation, electric utilities must split regulated from deregulated activities and compete with new firms originating from other energy businesses or retail services[3]. The economic decisionmaking mechanism, under competition, normally responds to a decentralized process whereby each participant maximize profit equal to the difference between total revenue and total cost. However, under competition, the recovery of investment in new plant is not guaranteed as a result of improper regulatory framework that exists in developing countries. So, risk management becomes a crucial part of the electricity business in developing countries[4].

Global competition promoted by international firms is emphasizing international price comparisons and, consequently, inducing nations to reduce electricity costs in order to be globally competitive. Restructuring and deregulation processes should be carried out by governments through the introduction of electricity markets to increase efficiency and reduce prices[5]. Markets also promote participation of external agents and neighboring countries with lower production costs as a way to achieve lower prices. These primary aims of restructuring energy sector cannot be achieved without new generation technologies, information and communication technologies that are still lacking in many developing countries.

The International Financial Institutions, such as World Bank (WB), International Monetary Fund (IMF) usually insist that a nation should decentralize her energy sector before funds could be granted to her for modernization and upgrading. An example of this could be seen in Ukraine when the country was in deep energy crisis after the breakdown of Soviet Union in 1993. The fund approved by the World Bank to rescue Ukrainian energy sector from crisis was too small to make any significant improvement[6]. Loan repayment and the payment for the expenses on their services according to the lending terms must be made by means of surcharges to the corresponding rates. This further worsenes the situation and the energy price increased instead of decreasing. In conclusion, establishement of power markets in Nigeria or in any developing country without sufficient generation capacity will results to an increase in the production costs.

\subsubsection{Fiscal Policy}

Fiscal policy can be grouped into two subgroups namely: taxation and subsidies.

\section{i. Taxation}

Fiscal policy refers to government policy that attempts to influence the direction of the economy through changes in government spending of taxes. If the tax is too high, it means that the energy power enterprises profits would be reduced. This in turn could make the energy enterprise less attractive to investors. This is one of the main reasons why majority of energy enterprises seek a way of tax holiday for the period of construction of power infrastructures that normally range from five to eight years depending on which type power stations. The reason for seeking tax holiday is to enable the power enterprises to maximize their profits especially in the short term. On the other hand, if tax is too low the government policy on direct investment as mentioned above will be reduced. In view of this, the effect of tax increase or tax reduction on energy sector should be critically analysed before the decision could be taken.

ii. Subsidies

It is observed that subsidies in power sector as seen in some vertically integrated utilities did not enhance efficiency unless there is competition in generation, transmission and distribution, which is one of the major motives that calls for deregulation of the sector in many countries. Political instability is a major problem that affects fiscal policy in developing countries. Political struggle in some countries have direct effect on the long - term planning of power system operation and management. Due to sensitive nature of energy sector to the welfare of the people, government always has to take absolute care in ensuring that its decision do not create rooms for the oppositions to criticize. For instance Latin American Countries had an experience in high rates of electricity demand and the state with a significant external debt, was unable to carry out the needed generation investments. Nuclear power industry was developed with high level of State support but political opposition has undercut this support, stopping new investment in nuclear plants[7]. Also in Ukraine, political opposition stopped the country from receiving investment capital (IC) from foreign countries for the construction of a new modern gas power plant and cancelled the proposed tax holiday that the investors are seeking from the Ukrainian government for the period of the construction of the new power plants[8]. The experience in Australia, where investments response has been in the face of robust growth in demand, suggests that governments need to carefully consider the implications of their policies and subsequent actions on private investors that the reforms are attempting to attract[11]. Traditionally, the electricity industry in developing countries exhibit natural monopoly characteristics. In order to achieve economic efficiency in a natural monopoly, industry requires regulation. According to economic theory of regulation (Joskow and Noll, 1981) which describes attempts to predict which institutional arrangement is preferable as a function of the comparative social costs and benefits of the following: 
government monopoly; private monopoly base, regulation and government/private monopoly with regulation The solution to each institutional arrangement mentioned above involves costs, including (1) the social cost of the monopolist using its market power, (2) the cost of maintaining a regulatory agency, and (3) the costs imposed on the monopolist by the regulator[10]. It is important to note that in most developing countries, besides the administrative costs associated with regulation, another potential cost arises from misguided regulatory interventions that can create social welfare losses. Therefore, the regulator must carefully consider the costs and benefits of each regulatory requirement on the regulatory agency and the regulated utility.

\subsubsection{Monetary Policy}

Monetary policy could also be divided into two groups namely interest rates and bonds.

\section{Interest Rates}

Monetary policy is another powerful tool that Government uses to stabilize economy. It is a process by which the government through central bank controls the money in circulation. It is mainly done through interest rates and bonds. Monetary policy could be expansion policy or contraction policy. In expansionary policy, the government increases the total money in circulation. This is normally achieved by lowering interest rates so that people can borrow money in cash to carry out production activities. The effect of this expansion policy on energy sector is that if appropriate measures are not put in place to increase the generation capacity, then there will be shortage of power supply. But on the other hand, if interest rates are too low, people will reluctantly save money in cash. This will in turn affect investment on long term basis and the situation could lead to cloudy - over in borrowing[11].

In contraction policy to combat inflation, means the Government will raise interest rate to encourage savings and retard production activities. This will also affect energy sector because high interest rate will lead to high cost of production and low profit from energy activities. In this case, the investment fund on energy sector in the long run, which could have been used for innovation and modernization of technologies, will be greatly reduced because of high interest rates. The high interest rates as observed in Nigeria and many other developing countries discourage both local and foreign investors from investing in power sectors.

In summary, government policy has great influence on the effective functioning of energy sector. It is also important to note that government policies are influenced by some other factors such as economy factor, natural factor, external factor, etc. The various types of government policies are illustrated in the figure 1.1 below:

\subsection{Economy Factor}

Economy of a nation refers to total wealth of that nation measured in Gross Domestic Products (GDP) or Gross
National product (GNP). Where there is an increase in GDP or GNP in a country, it is obvious that there will be misbalance in the demand and supply of energy. Increase in GDP or GNP means more use of materials for production activities. China and India for instance where there are tremendous increases in GDP can be taken as examples to analyze the current demand for energy consumption in those nations. On the other hand, when there is recession in the economy energy sector will be mostly affected since this sector is capital intensive and involves long term planning. During any recession period, a lot of business activities go bankrupt and this leads to lack of funds to pay for electrical energy. The economy of a nation could be influenced by different factors such as natural phenomena, government policy, and society/community factor as shown in figure 1.3. In deciding and adopting ways of improving efficiency and reliability of power supply, there must be a comprehensive and qualitative assessment of the economic potential of that nation/region.

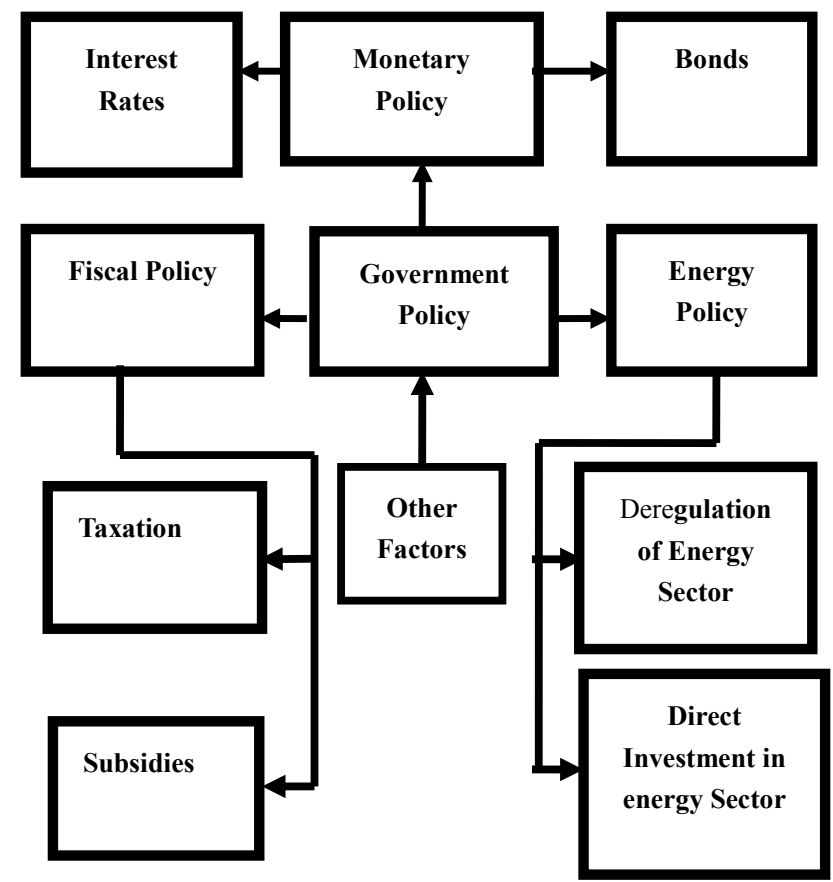

Figure 1.1. Types of Government Policy

\subsection{Society/Community Factor}

From the point of view of macroeconomics, it is clear that changes in the level of consumptions and composition of taxation and government spending can impact on the following variables in the economy:

- Aggregate demand and the level of economic activity.

- The pattern of resource allocation.

- The distribution of income.

These variables affect energy sector as mentioned in section 2.1 .

It is a common fact that if the government wants to get more funds from the society the government has to create more employment and allow the society/community to have self interest in the economic activities. This is the only way 
in which the efficiency of our limited resources could be enhanced. Adam Smith in his book "The Wealth of Nations" explained that all the activities of individuals in a society contribute much to the wealth of that nation, rather than the natural resources available in that nation. He further advises that "as every individual should endeavor as much as he can both to employ his capital in the support of domestic industry and so to direct that industry it produces may be of greatest value, every individual necessarily labors to render the annual values of society as great as he can". Smith said that self interest alone (in proper institutional setting) can lead to socially beneficial results. The idea laid by Smith is much more applicable in energy sector, since energy resources are limited and demand for it is unlimited. The task here is how to involve the individual and/or groups of individuals to have self interest in the activities of energy sector. The way out is simply to ensure that the individuals or groups of individuals should be made to invest in energy sector as mentioned above. This is self explanatory because as an individual, when you invest your capital in an enterprise, it is obvious that you will try all your best to see the success of that enterprise. Again, it is clear that when various forms of governmental parastatals, cooperate organizations and the private sector are directly involved in power sector, there would be efficiency in power supply in Nigeria.

\subsection{Effective Energy Management}

Energy management is the science involving planning, directing, controlling the supply and consumption of energy to maximize productivity and comfort and minimize the energy cost and pollution with conscious judicious and effective use of energy. There are two sides of energy management[9]. These are the Demand side of energy management and the Supply side of energy management. The aim of the supply side of energy management is to ensure supply of energy all the time, while the aim of the demand side is to optimize energy consumption. When there is effective energy management, there would be economic efficiency, because power producers would try to maximize their profits by using those generating units that minimize cost, while consumers would buy the energy at marginal cost of production. In developed countries, energy planning is deciding various activities in advance with reference time frame (short term , midterm and long time range) including forecast, budget, infrastructure planning and financial resources planning, technological planning, human resources planning, research and development planning, etc. Figure 1.2 illustrates flow chart of energy planning. Energy management and control systems (EMCs) have been evolved in practically all branches of energy generation, transmission and utilization in developed countries. This was achieved due to advancement in electronic, electromechanical, digital controls, online microprocessor based controls and use of personal computers and energy conservation software for optimizing the energy consumption and minimizing the energy losses in various places. The energy conservation feature is also provided in the closed loop control system such that at every prevailing load, the input is adjusted automatically to give maximum efficiency at that load[9]. But in most developing countries, EMCs are not yet fully utilized. A flow chart of energy planning is given in figure 1.2 and it shows that various data are collected and used to evaluate trends in order to determine demand for power consumption. When the energy demand has been established, then we can now analyze the resources that are available to meet up with the demands.

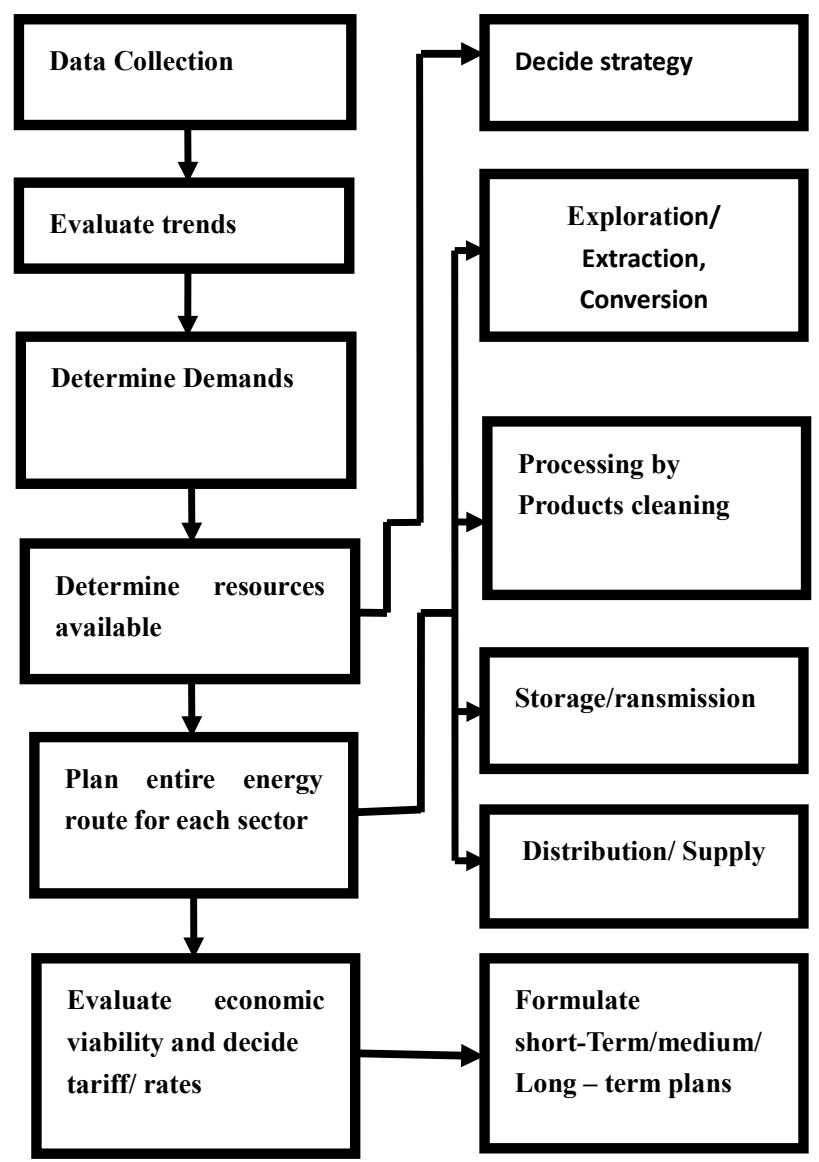

Figure 1.2. Flow chart of energy planning.

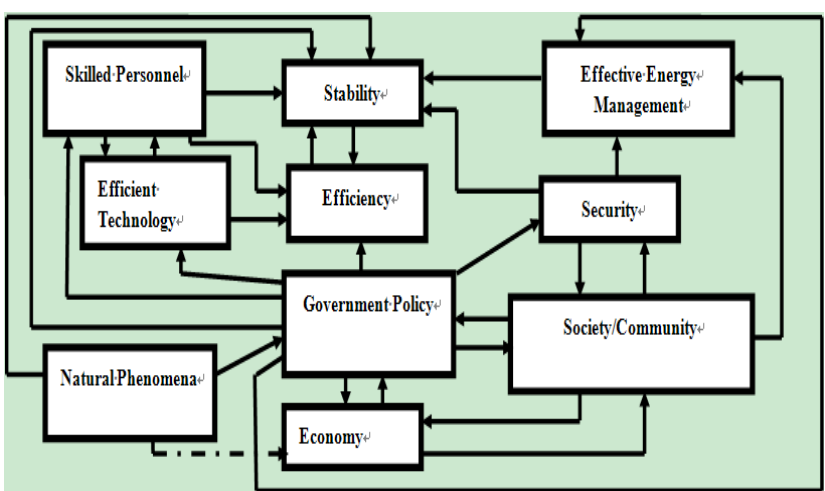

Figure 1.3. Interrelated factors affecting efficiency and stability of Power Supply

In summary, In order to have effective energy management, there must be proper energy planning for demand and supply side of energy management which will in turn 
improve the stability and efficiency of power supply in developing countries, and Nigeria especially.

\subsection{Skilled Personnel}

Human resources planning and management play a vital role in any production activity. In some developing countries, there seem to exist abundant human resources, but specialists in power sector are scarce. This is one of the major causes of delay in restoring any abnormality in power system grids in most developing countries. Trained personnel would be able to use modern sophisticated technologies and this will enhance efficiency. Investment in generation, transmission and distribution alone will not promote efficiency unless there is simultaneous investment in human resources and in research development.

\subsection{Efficient Technology}

The effect of technological innovation in recent years has helped to solve some problems affecting power sector in developed countries. Majority of power system equipment currently in use in various developing countries are obsolete and hence their output has dropped considerably. One of the problems Nigeria is currently facing in power system operation is the lack of efficient technology. Sometimes to even get some of the spare parts of those old equipment is a problem due to the fact that they are not technically and economical viable to manufacture. This is clear since power system equipment indices decrease as they get aged in operation. Efficient technology use has great impact on the stability of power supply. Maintaining stability in power supply and optimizing energy consumptions will lead to efficacy.

\subsection{Natural Phenomena}

We cannot ignore the fact that in some parts of the world, natural disasters do happen which may lead to serious destructions to power systems. Natural phenomena could be earthquake, flooding, drought, thunder storm (lightning strokes) etc. If adequate measures are not taken to restore the system on time, it could lead to severe economic problems to the power producers and consumers. The only solution to these problems are to have our grids properly protected against lightning phenomena and we should critically analyze all the imported equipments to test whether they are technically fit to be used in tropical developing countries like Nigeria. Many faults that do occur in Nigerian power lines especially during rainy season could be attributed to lightning strokes that result in equipment failure. The analysis of various outages in Mando $33 \mathrm{KV} / 11 \mathrm{KV}$ substation in north western Nigeria showed that the outage rates are more frequent in period between the Months of May to September which is the rainy season in the north central part of Nigeria. The major reason for these outages is the damage done to the overhead lines due to thunder strikes, heavy winds, storms and other disturbances associated with rain. These damages include; bending or falling of trees, breaking of the $33 \mathrm{KV}$ cross arm, shattering of the lighting arrestor and cracking of the insulator. On several occasions, automatic tripping of the circuit breaker results when there is bridging of conductors due to falling trees. The surrounding temperature also affects the performance of the equipment used in the network. Also, cloudy or windy atmosphere, dust particles and pollutant on the insulators can become conductive and create some leakage path to the ground for the current leading to flashover. Bridging of lines also occurs due to the action of birds, snakes, etc.

The effect of these natural phenomena on the energy sector could be listed as follows; extra expenditure for every consumer of electricity in an attempt to providing alternative source of power; Loss of revenue by public and government firms; Inefficiency in producing and manufacturing sectors of the economy; high cost of making services available and discouragement of investors. The best approach in minimizing the effect of natural phenomena on the power grid in Nigeria is to carryout extensive analysis of the possible natural phenomena including environmental conditions that could affect power system equipment. Having identified the possible natural phenomena and the environmental parameters that could affect the power grid, the proper protective measure can then be adopted.

Table 1.1 - Table 1.7 and graphs below show the results of the observations of the various outages for Mando substation in the north western part of Nigeria. Outage data were collected from Mando transmission substation, (PHCN) Kaduna. These data were recorded between January 2007 and October 2007.

Table 1.1. Outages for Mando Transmission station (33 KV)

\begin{tabular}{|c|c|c|c|}
\hline Period & $\begin{array}{c}\text { Scheduled Outage } \\
\text { Duration (min) }\end{array}$ & $\begin{array}{c}\text { Forced Outage } \\
\text { Duration (min) }\end{array}$ & $\begin{array}{c}\text { Total Outage } \\
\text { Duration (min) }\end{array}$ \\
\hline 1 & 2132.3 & 557.5 & 2689.8 \\
\hline 2 & 996.18 & 0 & 996.1 \\
\hline 3 & 1825 & 420.8 & 2245.8 \\
\hline 4 & 1524 & 1750.2 & 3274.2 \\
\hline 5 & 7246 & 5612 & 12858 \\
\hline 6 & 2062 & 996.38 & 3058.38 \\
\hline 7 & 4105 & 1988 & 6093 \\
\hline 8 & 3500 & 3730 & 7230 \\
\hline 9 & 4109.7 & 5462.1 & 9571.8 \\
\hline 10 & 5206 & 2430.4 & 7636.4 \\
\hline
\end{tabular}

Table 1.2. Outages for Kumbotso substation (33KV)

\begin{tabular}{|c|c|c|c|}
\hline Period & $\begin{array}{c}\text { Scheduled Outage } \\
\text { Duration(min) }\end{array}$ & $\begin{array}{c}\text { Forced Outage } \\
\text { Duration(min) }\end{array}$ & $\begin{array}{c}\text { Total Outage } \\
\text { Duration(min) }\end{array}$ \\
\hline 1 & 3287 & 1000.6 & 4287.6 \\
\hline 2 & 3527.4 & 1688.34 & 5215.74 \\
\hline 3 & 2224 & 262.4 & 2486.4 \\
\hline 4 & 2226 & 1417.5 & 3643.5 \\
\hline 5 & 4205 & 3102.4 & 7307.4 \\
\hline 6 & 18250 & 4325 & 22575 \\
\hline 7 & 20406 & 5843.4 & 26249.4 \\
\hline 8 & 10400 & 7030 & 17430 \\
\hline 9 & 10226 & 7172.98 & 17398.98 \\
\hline 10 & 8450 & 5133 & 13583.4 \\
\hline
\end{tabular}


Table 1.3. Outage Model for Kaduna township transmission substation $(33 \mathrm{KV})$

\begin{tabular}{|c|c|c|c|}
\hline Period & $\begin{array}{c}\text { Scheduled Outage } \\
\text { Duration(min) }\end{array}$ & $\begin{array}{c}\text { Forced Outage } \\
\text { Duration (min) }\end{array}$ & $\begin{array}{c}\text { Total Outage } \\
\text { Duration (min) }\end{array}$ \\
\hline 1 & 1565.6 & 776.36 & 2341.98 \\
\hline 2 & 562.2 & 0 & 562.2 \\
\hline 3 & 1025.6 & 422.2 & 1447.8 \\
\hline 4 & 1505 & 1132.6 & 2158.2 \\
\hline 5 & 1200 & 521.4 & 1721.4 \\
\hline 6 & 3764 & 754 & 4518 \\
\hline 7 & 4207 & 467 & 4674 \\
\hline 8 & 2700 & 1800 & 4500 \\
\hline 9 & 2756 & 4204.78 & 5160.78 \\
\hline 10 & 1525 & 1680.56 & 3205.56 \\
\hline
\end{tabular}

Table 1.4. Outage for Dan Agundi Transmission Substation (33 KV)

\begin{tabular}{|c|c|c|c|}
\hline Period & $\begin{array}{c}\text { Scheduled Outage } \\
\text { Duration (min) }\end{array}$ & $\begin{array}{c}\text { Forced Outage } \\
\text { Duration (min) }\end{array}$ & $\begin{array}{c}\text { Total Outage } \\
\text { Duration(min) }\end{array}$ \\
\hline 1 & 756.7 & 659.3 & 1416 \\
\hline 2 & 165.2 & 166.6 & 331.8 \\
\hline 3 & 1000 & 418.2 & 1480.2 \\
\hline 4 & 787 & 576.8 & 1363.8 \\
\hline 5 & 912 & 861.6 & 1773.6 \\
\hline 6 & 4020 & 2869.8 & 6889.8 \\
\hline 7 & 1525 & 195.2 & 1720.2 \\
\hline 8 & 860 & 640 & 1500 \\
\hline 9 & 525 & 360.6 & 885.6 \\
\hline 10 & 607 & 506 & 1113 \\
\hline
\end{tabular}

Table 1.5. Outage Model for Funtua Transmission Substation (33KV)

\begin{tabular}{|c|c|c|c|}
\hline Period & $\begin{array}{c}\text { Scheduled Outage } \\
\text { Duration (min) }\end{array}$ & $\begin{array}{c}\text { Forced Outage } \\
\text { Duration (min) }\end{array}$ & $\begin{array}{c}\text { Total Outage } \\
\text { Duration (min) }\end{array}$ \\
\hline 1 & 1700 & 2027.8 & 3737.8 \\
\hline 2 & 920 & 502 & 1422 \\
\hline 3 & 1725 & 955.2 & 2680.2 \\
\hline 4 & 2768 & 1464.4 & 4232.4 \\
\hline 5 & 2560 & 1110.8 & 3670.8 \\
\hline 6 & 18706 & 3686.6 & 22384.6 \\
\hline 7 & 15607 & 5479.58 & 21086.58 \\
\hline 8 & 9085 & 7320 & 16405 \\
\hline 9 & 11200 & 7202 & 18402 \\
\hline 10 & 10204 & 5787.6 & 15996.6 \\
\hline
\end{tabular}

Table 1.6. Outage Model for Dakata Transmission Substation (33KV)

\begin{tabular}{|c|c|c|c|}
\hline Period & $\begin{array}{c}\text { Scheduled Outage } \\
\text { Duration(min) }\end{array}$ & $\begin{array}{c}\text { Forced Outage } \\
\text { Duration (min) }\end{array}$ & $\begin{array}{c}\text { Total Outage } \\
\text { Duration (min) }\end{array}$ \\
\hline 1 & 912 & 36.6 & 948.6 \\
\hline 2 & 1118 & 111.4 & 1229.4 \\
\hline 3 & 896 & 340 & 1236 \\
\hline 4 & 1542 & 1500 & 3042 \\
\hline 5 & 2617 & 1938 & 4603 \\
\hline 6 & 2908 & 2646.2 & 5554.2 \\
\hline 7 & 4270 & 3644.42 & 7914.42 \\
\hline 8 & 6729 & 4107 & 10836 \\
\hline 9 & 11920 & 7920.9 & 19840.98 \\
\hline 10 & 1870.2 & 1827.6 & 3697.8 \\
\hline
\end{tabular}

Table 1.7. Outage Model for Kankia Transmission Substation (33KV)

\begin{tabular}{|c|c|c|c|}
\hline Period & $\begin{array}{c}\text { Scheduled Outage } \\
\text { Duration (min) }\end{array}$ & $\begin{array}{c}\text { Forced Outage } \\
\text { Duration (min) }\end{array}$ & $\begin{array}{c}\text { Total Outage } \\
\text { Duration (min) }\end{array}$ \\
\hline 1 & 1203 & 489 & 1692 \\
\hline 2 & 52.8 & 0 & 52.8 \\
\hline 3 & 1458 & 1000 & 2458 \\
\hline 4 & 1569 & 1888.8 & 3457.8 \\
\hline 5 & 5020 & 3588.8 & 3608.8 \\
\hline 6 & 16700 & 9883 & 26583 \\
\hline 7 & 12206 & 2860.6 & 15066.6 \\
\hline 8 & 68502 & 51943 & 120456 \\
\hline 9 & 6764 & 4481.8 & 11245.8 \\
\hline 10 & 1928.8 & 1769 & 3697.8 \\
\hline
\end{tabular}

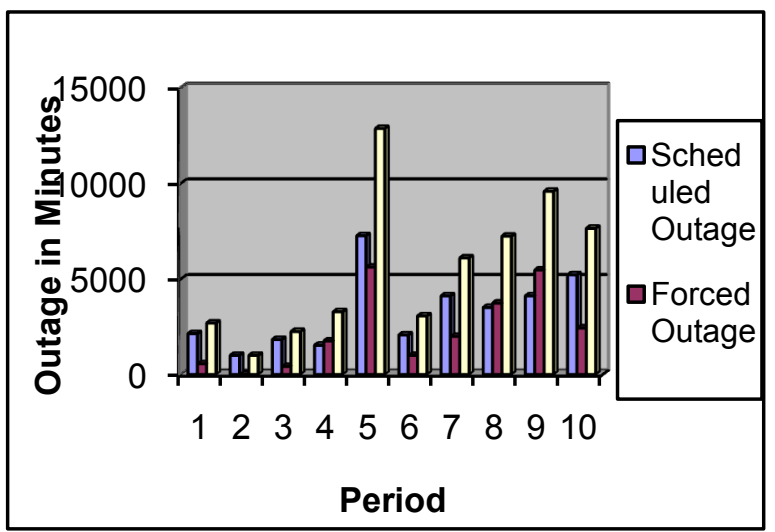

Figure 1.1.a. Varition of Outage Overtime for Mando Transmition Substion

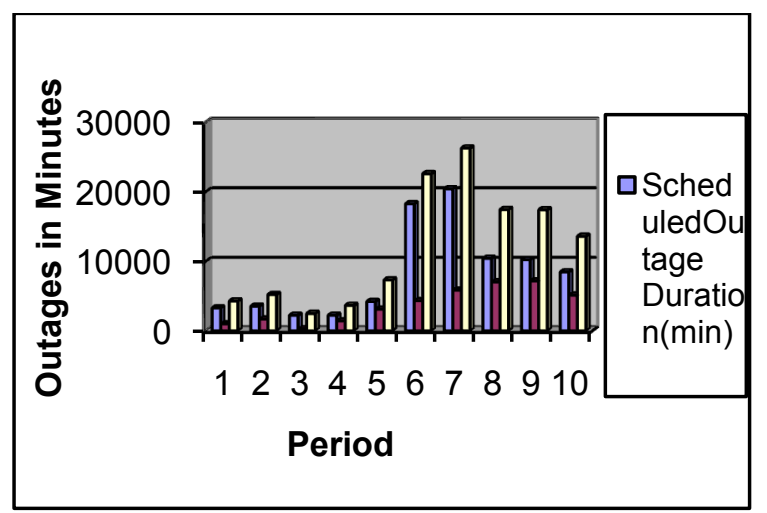

Figure 1.1.b. Varition of Outage Overtime for Mando Transmition Substion

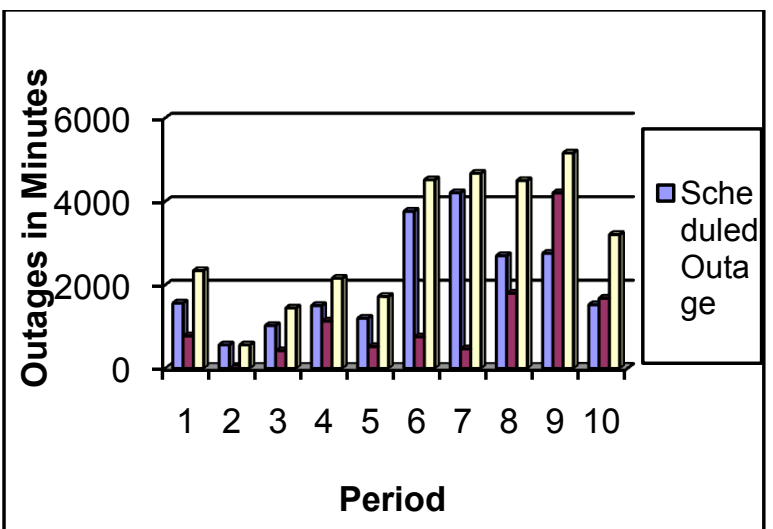

Firure 1.1.c. Variation of outage Over Time For Kaduna Township Transmition Substation 


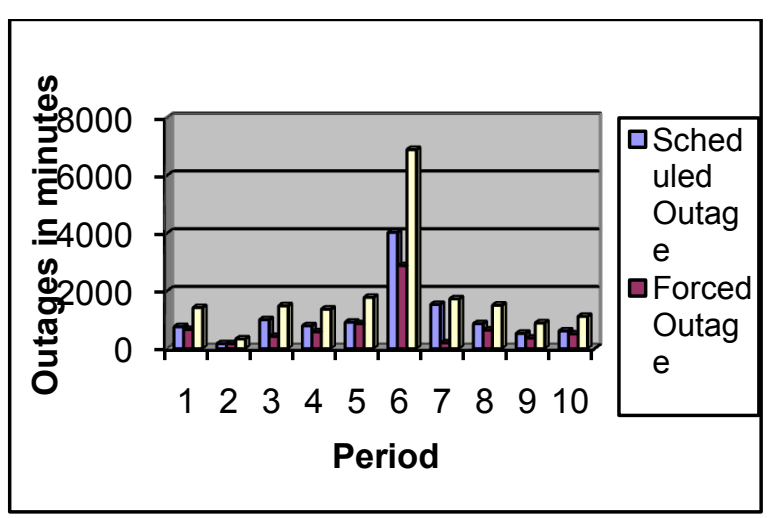

Figure 1.1.d. Variiation of outage for Dan Agundi Transmition Substation

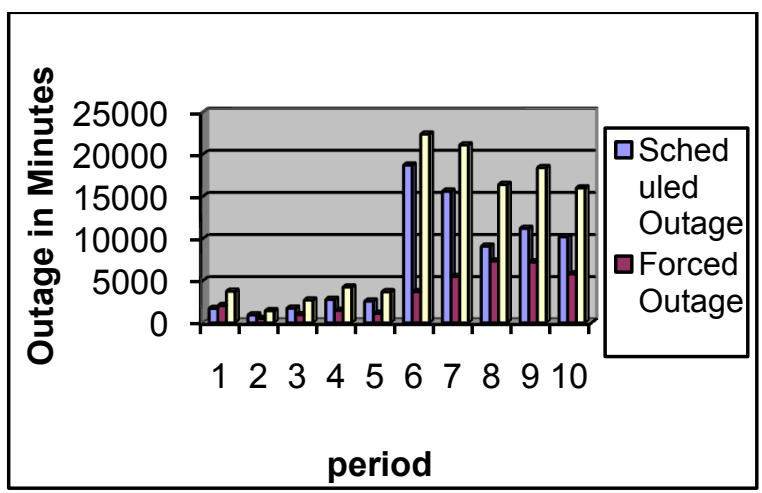

Figure 1.1.e. Variation of Outage for Funtua transmition Substation

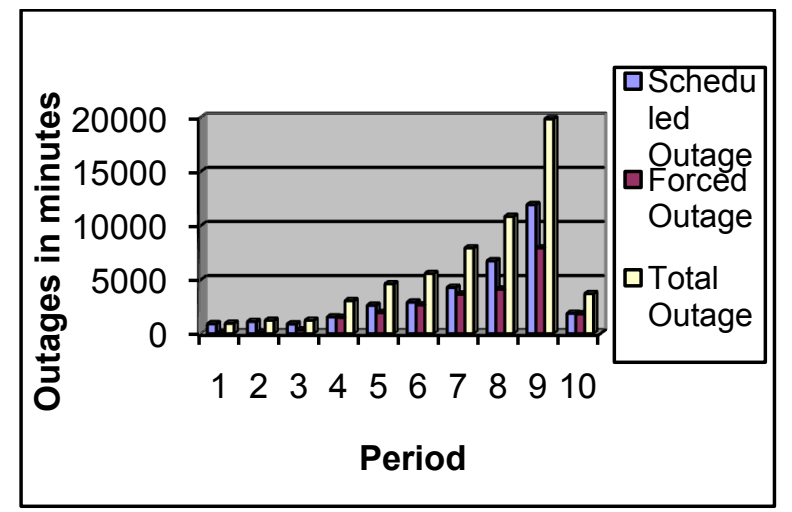

Figure 1.1.f. Variion of outage for Dakata Transmition Substation

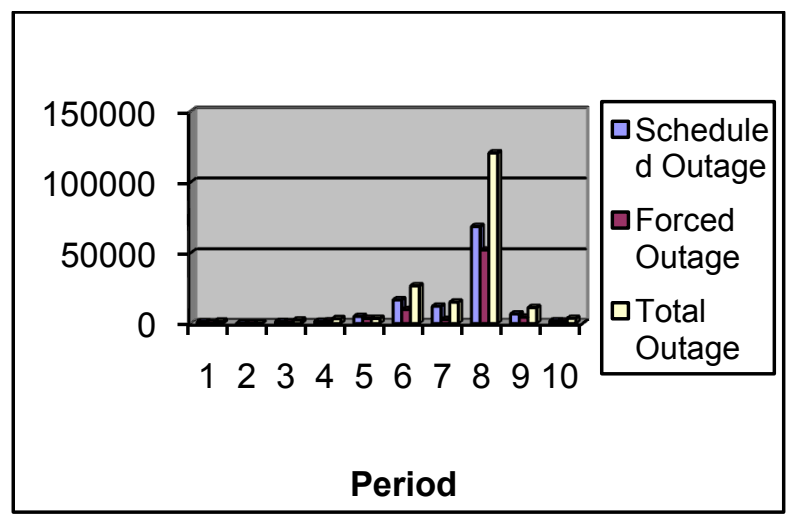

Figure 1.1.g. Variation of Outage for Kankia Transmition Substation

Figure 2. Outages in Minutes for 7 substations
From the tables and graphs illustrated above, it can be seen that in various $33 \mathrm{KV}$ Transmission Stations been observed, the outages are high in the Month of August to September. This range of time is the period where the lightning or thunder storm hit the transmission substation frequently. In conclusion, Natural phenomena such as lightning and thunder storm contributed a lot to power failure in Nigeria.

\section{Recommendation to Find Solutions to the Complex Problems Affecting the Energy Sector in Nigeria, the Following Recommendations are Required}

- There is need to extensively evaluate the potential of all the primary energy sources available in the country. This will give an insight on where to put more investments.

- Any decision to be taken concerning restructuring of the energy sector should be based on technical - economic background rather than politically motivated considerations.

- There should be a well defined legal framework to guide all the stakeholders of energy sector.

- Primary energy sources such as coal, gas and petroleum sector should be deregulated.

- Imported power equipment should be subjected to rigorous standards tests.

- The Power Holding Company of Nigeria (PHCN) should make all their data transparent and accessible for academic research.

- Individuals or groups of individuals should be encouraged to participate in the energy activities.

- There should be more investment in research and human resources. This will enhance professionalism in technical and management skill.

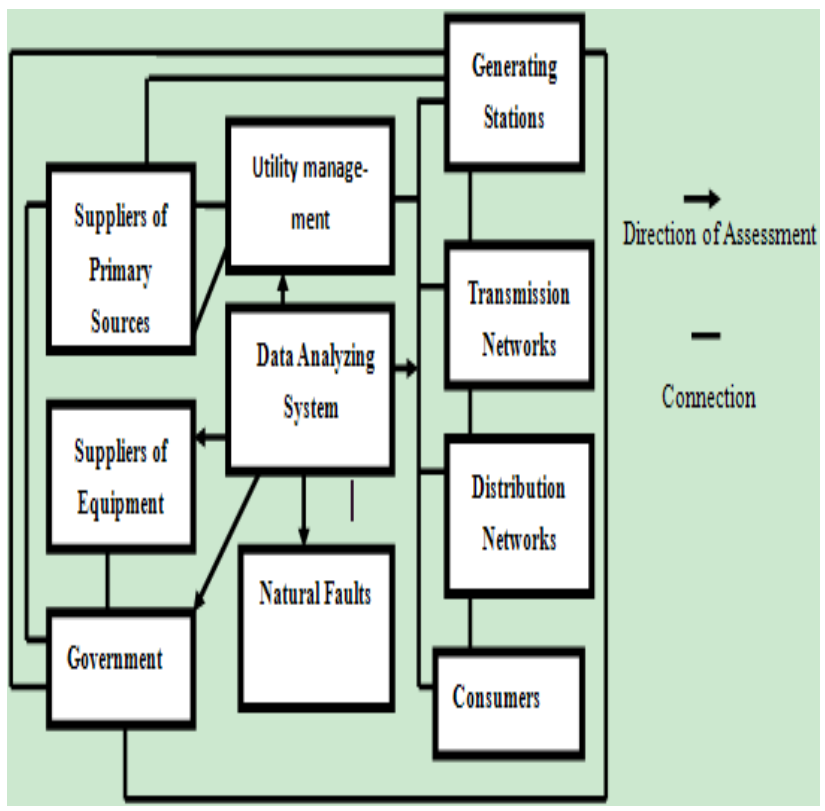

Figure 1.4. Total Energy Management 
- The Government should introduce total energy management (TEM) as shown in figure 1.4

- There must be a data analyzing system that would be controlled and managed by separate legal entity as shown in figure 1.4.

\section{Conclusions}

In conclusion, the factors affecting energy sector in Nigeria are complex and interrelated in nature. To improve efficiency and reliability of power supply, these complex interrelated factors should be critically evaluated. Restructuring of energy sector in Nigeria should be done in stages in order to attract foreign and local investors. There should be enough generation capacity before initiating deregulation in order to avoid price hike as a result of power shortage. The inadequacy of power supply in Nigeria has technical and economical disadvantages which could lead to catastrophic recession in the economy. The technical implication of starting up or shutting down a thermal generating unit or even increasing or decreasing its output is considerable mechanical stress in the prime mover [3]. Excessive stress damages the plant and shortens its lifespan. When a thermal generating unit is frequently being shut down and started-up as observed in Nigeria, it leads to high cost of electrical energy. This is because of the cost incurred in getting this unit running and ready to produce from a shut down state. The recommendations given in this paper are arguably the best ways to enhance stability and improve efficiency in electric power sector of the country.

\section{ACKNOWLEDGEMENTS}

The Authors wish to acknowledge the contributions of Ishaya D. Ishara and staff of Mando $33 \mathrm{KV}$ transmission substation, Kaduna, Nigeria for making available, all relevant data used in this paper.

\section{REFERENCES}

[1] Daniel S. Kirschen, Gordon Strbac, "Fundamental of power System Economics," John Wiley \& Son Ltd, England 2004

[2] Oricha J.Y Analysis of Interrelated Factors Affecting Efficiency and stability of Power Supply in Developing Countries. IEEE AFRICON 2009, Nairobi, Kenya

[3] Oricha J.Y, Dissertation "Economic Analysis, Options of Organization of Energy Market interaction" Institute of Economic Pragnosing of National Academy Sciences of Ukraine, Kyiv, 2000

[4] Nedin I.V, Ryzhov V. V, Oricha J, Chastockolenko P.I, "Influence of Subjective Factors on effectiveness of energy Market Liberalization", Proceedings of the Russian National Symposium on Power Engineering, Volume II, PP 209-212, 2001

[5] Steven Karekezi \& Timothy Ranja, "Renewable Energy Technologies in Africa”, Zed Books Ltd, London, 1997

[6] The Energy Journal, International Association for Energy Economics, USA, Volume 17, No. 4, 1996

[7] "Comparative Analysis of Crisis in Electricity Sector in Emerging Economy", Proceedings of the $1^{\text {st }}$ National Engineering Conference, Nigeria, Volume One, PP.140-144, 2008

[8] Maths H.J Bollen, "Understanding Power Quality Problems", IEEE Press, 2000

[9] G. A. Cole, "Management Theory and Practice", Fifth Edition, London, 1996

[10] Jizhong Zhu Optimization of Power System Operation published by John Wiley \& Son, Inc, 2009

[11] Peter Fraser "Power Generation Investment in Electricity Markets"' International Energy Agency 2003

[12] The Nigerian Electricity Regulatory Commission "Guide to the development of Independent Power plants. 2008 